\title{
Reservations about Rushton
}

\author{
James R. Flynn \\ Department of Psychology, University of Otago, 362 Leith St, North Dunedin, Dunedin 9016, New Zealand; \\ jim.flynn@otago.ac.nz
}

Received: 20 December 2018; Accepted: 1 February 2019; Published: 11 February 2019

\begin{abstract}
Rushton believed not only that East Asians, whites, and blacks could be ranked in that order for desirable traits but also that the black/white IQ gap is predominantly genetic in origin. Concerning the first, he relied on the "ice ages hypothesis"to show that the evolutionary history of the three races had varied as East Asians were subjected to the most demanding environment (north of the Himalayas), whites to the next most demanding (north of the Alps), and blacks to the least demanding (Africa). As to the second, he appealed to arguments based on the method of correlated vectors (Jensen effects) and regression to the mean. To assess his contribution I argue: (1) That the racial ranking for desirable traits is not as tidy as it seems; (2) That the ice ages hypothesis has been falsified; (3) That the black/white Q gap is more likely to be environmental, with black American subculture as the culprit; and (4) That appeals to correlated vectors and regression cannot disentangle genetic and environmental causes.
\end{abstract}

Keywords: Rushton; black/white IQ gap; black subculture; correlated vectors; regression to the mean; the "ice ages" hypothesis

\section{Introduction}

It is a pleasure to comment in a forum in which reason and evidence replace invective. Before moving on to method, I wish to make a general comment. It is now universally accepted that the Chinese are specially subject to pathological gambling. The UCLA Gambling Studies Program estimates that in the U.S., the rate of gambling addiction ranges from $6 \%$ to nearly $60 \%$ (depending on the specific Asian ethnicity) as opposed to the national rate of 1-2\% [1]. Surely this counts against Rushton's ranking of Orientals as the most cautious and least impulsive.

This tendency towards impulsivity is present from an early age. Using data collected by Lynn et al. (1991) [2] and Flynn (1991) [3], we analyzed performance on the odd-button-out RT (reaction-time) task. The analysis involved school children who had their finger on a home button and must move it to a target button (atypical either in lighting up or not lighting up). It yields two measurements: decision time (the time it takes to release the home button), and movement time (once the home button is released, the time it takes to reach the target button). The data showed that Chinese children turn out to be risk takers. As soon as there is a flash of light, they take their finger off the home button and "think" their way to the correct target button. On the other hand, British children are cautious. They will not leave the home button until they "know" which target button they are to arrive at. The result, of course, is that Chinese children have a faster decision time (DT), and British children have faster movement time (MT).

Perhaps we could salvage Rushton on this point by introducing a distinction; Chinese are more impulsive when interacting with a "machine" (roulette wheel, reaction-time apparatus) and less so than when interacting with people (submitting to the temptation of unprotected sex). This would at least qualify the generalization. Do blacks cheat on their income tax more often than Chinese? If so, this is a much more sensible "impulsivity" than thinking you can beat the odds at a casino. 


\section{Method of Correlated Vectors}

When American blacks and whites are compared on the 10 Wechsler subtests, the performance gap between them increases the more highly g-loaded the test. This is essentially a correlation with a rising degree of cognitive complexity. The gap is small on digit span forward, which is merely repeating random numbers in the order they were read out. It is greater on digit span backward, which involves repeating numbers in the reverse order to which they were read out, a clearly more complex task. The $g$ loading of a subtest also measures the degree to which a subtest predicts overall cognitive competence. Indeed, the very meaning of a high $g$ loading is that the score on that test does a better job of predicting performance on the Wechsler battery as a whole: one's overall IQ or one's $g$ (general intelligence factor). This is because IQ competence is captured to some degree by each subtest and they are all correlated with one another (have a positive matrix).

This phenomenon, that two groups systematically differ in terms of a rising performance gap with increased cognitive complexity, I will call the " $g$ pattern". It is often called a "Jensen effect". Ruston considers it evidence that the group that falls further behind suffers from an intelligence deficit, one genetic in origin. In fact, there is a potential $g$ pattern wherever there is: (1) a general competence; (2) that can be partitioned into a number of tasks; (3) which are inter-correlated; and (4) form a complexity hierarchy.

Take driving a car as a competence that involves a complexity hierarchy: turning on the ignition; ordinary city driving; beltway (or ring road) driving; and parking. The better the driver, the more they will open up a gap on the average person as you ascend this hierarchy. If you compare two groups, they may well be equal for starting the car, one a bit better for ordinary city driving, and that group better still for beltway driving. The beltway has cars going at high speeds, often shifting lanes, and a host of entrances and exits, indeed, it is one of the first things many drivers give up as they age. There are many reasonable drivers who are bad at parallel parking and it is the task that those taking a driving test fear most of all.

Now the mere existence of a $g$ pattern (a rising gap between the best and the average as you go up this scale) does not tell you the cause of the pattern. You must diagnose that independently. For example, one group may be country drivers newly arrived in the city, unaccustomed to its traffic, never having confronted a beltway, and used to having plenty of space where you can do a drive-in park. So an environmental hypothesis about causality seems probable. Or the two groups may be all experienced city drivers and some inherited trait (ease or difficultly in spatial visualization) may differentiate them.

\section{Basketball}

You can find $g$ patterns everywhere in ordinary life that could be either environmental or genetic in origin, but tell you nothing simply by their very existence. Here, I will use a basketball example better than those I have used in the past. You are presented with players who have never played and your job is to turn them into a good team. You can aim high because you have reason to believe (from the performance of their parents and siblings) that they have high potential. You must train their skills up to whatever optimum is possible.

I will divide them into "groups" at various stages along the road toward the optimum result, the point at which training has had its maximum effect. For example, the group before training has even started, the group $25 \%$ of the way along the road, and the group half way along the road-all of these to be compared to a group when training is completed. This automatically controls for genes-we will assume that they are not in a growth spurt that would introduce biological as distinct from social factors (the training regime).

I will use an absolute standard of measurement (how many shots out of 10 you can make), rather than what we must settle for in IQ test data (how many SDs (standard deviations) above or below the average for my age on a given task). This was the objective that Jensen sought when he tried to equate cognitive performance with reaction times. The later were an "anchor" that allowed you 
to compare performances on an absolute scale, for example, measuring height using the markings on a tape measure [4,5]. He once likened IQ scores as trying to measure without any true ratio scale properties, rather like to trying to measure the tentacle length of octopuses by tasks based on what they could reach.

Basketball is a competence that can be partitioned into a variety of skills ranked by complexity. I will assume what every coach knows: training improves easy tasks more quickly than complex tasks. For example, at half way, compared to when the training regime is completed, they will be near equals for making lay-ups, getting there for foul shots, still a sizable gap for set shots outside the three-point line, and a big gap for fade-away jump shots. The data I present is illustrative, not based on results from real-world coaches.

Table 1 shows some surprising results. Group A represents what we could hope to achieve by the time the training regime is finished: 10 out of 10 lay-ups diminishing to 5 out of 10 fade-aways. (1) First comparison: Group B shows our players at halfway. As the complexity of the task increases, their performance falls further and further short of the optimum, and the performance gap between the two groups rises. This is an example where two groups are separated purely by environmental differences and where the $g$ pattern (or Jensen effect) occurs. (2) Second comparison: Group C shows our players before they begin, utterly clueless what a basketball is and what you are supposed to do with it. As the complexity of the task increases, their nil performance is closer and closer to the optimum. This is an example of a case where the two groups are separated purely by environmental differences, and you get a powerful anti-Jensen effect. (3) Third comparison: Group D shows our players about $25 \%$ of the way along their path. As the complexity of the task increases, their performance is exactly the same distance from the optimum. This is a case in which two groups are separated by environmental differences and you get a nil (or neutral) Jensen effect.

Table 1. Basketball training and the Jensen effect.

\begin{tabular}{|c|c|c|c|c|c|}
\hline & \multicolumn{5}{|c|}{ Task Complexity } \\
\hline & Layups & Foul Shots & Long Set Shots & Fade-aways & Quality of Environment \\
\hline Group A performance & $10 / 10$ & $7 / 10$ & $6 / 10$ & $5 / 10$ & Better (training done) \\
\hline Group B performance & $9 / 10$ & $5 / 10$ & $3 / 10$ & $1 / 10$ & Worse (half trained) \\
\hline A-B performance gap & $1 / 10$ & $2 / 10$ & $3 / 10$ & $4 / 10$ & \\
\hline \multicolumn{6}{|c|}{ A-B performance gap rises with greater complexity $=$ classic Jensen effect } \\
\hline & \multicolumn{5}{|c|}{ Task Complexity } \\
\hline & Layups & Foul Shots & Long Set Shots & Fade-aways & Quality of Environment \\
\hline Group A performance & $10 / 10$ & $7 / 10$ & $6 / 10$ & $5 / 10$ & Better (training done) \\
\hline Group C performance & $0 / 10$ & $0 / 10$ & $0 / 10$ & $0 / 10$ & Worse (clueless) \\
\hline A-C performance gap & $10 / 10$ & $7 / 10$ & $6 / 10$ & $5 / 10$ & \\
\hline \multicolumn{6}{|c|}{ A-C performance gap falls with greater complexity $=$ anti-Jensen effect } \\
\hline & \multicolumn{5}{|c|}{ Task Complexity } \\
\hline & Layups & Foul Shots & Long Set Shots & Fade-aways & Quality of Environment \\
\hline Group A performance & $10 / 10$ & $7 / 10$ & $6 / 10$ & $5 / 10$ & Better (training done) \\
\hline Group D performance & $5 / 10$ & $2 / 10$ & $1 / 10$ & $0 / 10$ & Worse (25\% trained) \\
\hline A-D performance gap & $5 / 10$ & $5 / 10$ & $5 / 10$ & $5 / 10$ & \\
\hline \multicolumn{6}{|c|}{ A-D performance gap static with greater complexity = nil Jensen effect } \\
\hline
\end{tabular}

Te Nijenhuis, Choi, van den Hoek, Valueva, E., and Lee (in press) [6] refer to the possibility of such cases as "anomalies", but they are actually counterexamples. If they occur, they simply refute the hypothesis that the existence of a $g$ pattern (they always call it a "Jensen effect') signals a genetic gap between a high and low scoring group. All three comparisons are environmental, no matter whether you get a $g$ pattern, an anti- $g$ pattern, or a nil $g$ pattern.

If you were to compare two really different teams in the real world, both of which had optimal training, you might well discover that genetic differences lay behind a $g$ pattern. Measure the two for something heritable, like height. Taller players might have a better chance of shooting over a defender on a fade-away jump shot, which would encourage a classic $g$ pattern: the better team would tend to 
outperform the worse team more on a complex task. However, this might be outweighed if tall people had a bigger advantage on lay-ups (they can slam-dunk and never miss), which would encourage an anti-g pattern: the better team would tend to outperform the worse team more on a simple task.

\section{A Problem for IQ Gains Over Time}

However, let us leave the world of basketball for the world of cognition. Once again, I will argue that the existence of a $g$ pattern poses problems of causality rather than settling them, or at least indicating whether genes or environment are responsible.

Te Nijenhuis, Choi, van den Hoek, Valueva, E., and Lee (in press) [6] cite studies showing that training on cognitive tasks produces the largest standardized gains on the easiest items, and the smallest standardized gains on the most difficult items [7,8]. Quite rightly, they take this as evidence of the existence of an anti-Jensen effect. If we divided a training group into two "groups"; one before training and one after training, the befores would exibit a smaller and smaller gap compared to the afters, as cognitive complextiy ( $g$ loadings) increased.

This raises a profound question about IQ gains over time. Why do they not show the maximum anti-g pattern? After all, throughout the 20th century, American sociey has "trained" its people to get higher scores on IQ tests. According to the training literature, the score rise on the simpler tasks should have been far greater than that on the harder items (the more complex ones). It is noteworthy, that if we took such a $g$ pattern at face value, it would imply that genetic enhancement was overwhelmingly responsible for IQ gains. Or we could have waited until we had used the method of correlated vectors on IQ gains, which shows that they have a very mild Jensen effect, just a slight corellation with more gains on lower $g$-loaded tests. We would have been puzzled, but taking that as our guide, would have presumed that enhanced genes would at least match enhanced environment as causes.

Fortunately, we approached the problem without prejudice. Hypotheses in favor of hybrid vigor were falsified and other hypotheses advanced, thanks largely to Woodley; who states that, if anything, genes deteriorate over time and cause IQ loss-if powerful environmental factors had not overwhelmed them and produced a huge gain. But why have the gains not shown a powerful Jensen effect?

My hypothesis is that since the 1900s, two things caused gains on high $g$-loaded tests. At that time, people did not have mind habits that allowed for good performance on items that demanded classification of the world to comprehend it, and the use of logic freed from reference to the concrete world [9-11].

Society demanded the development of those cognitive skills, which provided a platform for gains on high g-loaded tests. However, it also demanded better skills on low g-loaded tests such as memory - skills for which the friendly habits of mind were already in place in 1900. Given equal platforms in the 1900s, the latter would have been greater than the former. But the development of high- $g$ platforms plus a slower tendency to build on them once developed, just about equaled the non-development of low- $g$ platforms plus a faster tendency to build on them. Thus we got what we have; roughly the same gains irrespective of $g$-loading-all of which took place within the assumption of an envrionmental enhancement that cast genetic factors into the shade.

In conclusion, taking the presence or absence of a Jensen effect as a guide would have blurred the casual problem badly. It would have been as disastrous as jumping all over the place when confronted with basketball gains. Jensen effects between groups with higher or lower IQ means pose problems. But as always, deep causal analysis of environmental differences between the groups may (or may not) hold the key to explaining the IQ gap between them.

\section{Blacks in America}

Rushton and Jensen [12] summarize the evidence published by Nyborg and Jensen [13]. They analyzed a battery of 19 highly diverse cognitive tests from a data set of 4,462 males who had served in the U.S. Armed Forces. The average correlation between race differences on a test 
and its $g$ loading was 0.81. Nagliari and Jensen [14] used the WISC-R (Wechsler Intelligence Test for Children-Revised) to test a sample of 172 pupils in the fourth and fifth grades, of three schools in the central district of Columbus, Ohio. Each black child $(\mathrm{N}=86)$ was matched with a white child on age, school, sex, and SES (Socio-Economic Status), resulting in 86 black-white matched pairs. The WISC-R gave a correlation of 0.83 . Brody [15] pointed out something of considerable interest; if you dropped very low $g$-loaded subtests from the WISC battery, this lowered the result. He records Jensen's reply: that if you divided the subtests into those above and below the median $g$-loading, the results were very much the same.

However, that does not justify keeping low $g$-loaded subtests. You have two groups of subjects, assume one group does better than the other on a low $g$-loaded test, which is by definition an inferior predictor of overall cognitive competence. Then the two groups perform similarly on higher subtests that are really good predictors. The better performance on the low subtest now counts against you. After all, as you go up the scale your advantage over the other group diminishes from an advantage to no advantage - the method of correlated vectors makes it look as if you lose ground with cognitive complexity. How much better to do worse on the low g-loaded test and not be suspected of suffering from a genetic deficit!

\section{Blacks in Germany}

There is one piece of evidence that counts in favor of an environmental explanation about U.S. blacks and whites. Assume that in America, blacks show a $g$ pattern compared to whites. While in Germany, when whites and half-blacks are compared, the $g$ pattern disappears. This suggests that the presence or absence of a $g$ pattern has a cultural context.

After World War II, America maintained an occupying army in Germany. Eyferth selected a representative sample of the children black servicemen fathered with German women, and a matching group (matched for the SES of the mothers) of the children of white servicemen [16]. He collected IQ data for 170 of the former and 69 of the latter on the HAWIK or the German version of the WISC. Moreover, he compared the scores of blacks and whites on 11 subtests of the WISC. The eleventh was Digit Span, which I have omitted because it is not used in calculating full scale IQs. The question arises: when black and white genes are taken completely out of the American context and transplanted into Germany, what happens to $g$ ?

Table 2 applies the method of correlated vectors, and details the results. I have put what I consider the best correlation in bold: the Spearman with all ten conventional subtests including Coding. It gives an essentially nil value of +0.079 , which means less than $1 \%$ of variance explained. This is the correlation when $g$ loadings are derived from the HAWIK itself. The result is also nil (or +0.006 ) when the $g$ loading values are derived from the American WISC-R.

Table 2. Results when the method of correlated vectors is applied to the WISC sub-test performance of white and half-black children raised in Germany [10].

\begin{tabular}{ccc}
\hline Correlation Coefficient & Correlation & Source of $g$ Loadings \\
\hline Spearman without Coding & -0.367 & American WISC-R \\
Spearman with Coding & +0.006 & American WISC-R \\
Spearman without Coding & -0.267 & German HAWIK \\
Spearman with Coding & $\mathbf{+ 0 . 0 7 9}$ & German HAWIK \\
Pearson without Coding & -0.386 & American WISC-R \\
Pearson with Coding & +0.250 & American WISC-R \\
Pearson without Coding & -0.245 & German HAWIK \\
Pearson with Coding & +0.418 & German HAWIK \\
\hline
\end{tabular}

Two things counted against the other results; blacks did better on Coding compared to whites than on any other subtest, outscoring them by the equivalent of 2.3 IQ points. Coding had by far the lowest g loading: a loading of 0.442 compared to a range of 0.657 to 0.908 on the other nine subtests. 
Thus, it is a classic case of an advantage on a poor predictor making it appear as if a group was losing ground on a hierarchy of good predictors of overall performance. This suggested dropping Coding entirely. However, our statisticians argued against this (it might seem like a fiddle). They advised using a Spearman coefficient on all ten subtests, rather than a Pearson. They said with an array of only 10 comparisons, the Pearson was too much distorted by one outlier (Coding) while the Spearman was less so.

No matter how you choose among the results, all of them suggest that half-blacks do not lose ground on whites with increasing cognitive complexity when they are raised by white German mothers in Germany-at least not when you select good predictors of overall performance. To penalize them for doing well on Coding (a bad predictor) is to be a slave to a method while forgetting why it is significant.

\section{Black American Subculture}

We have only one relevant study and the numbers are small. However, it engenders a hypothesis that black American subculture handicaps blacks because it does not condition them to address complex cognitive problems. We must ask whether or not there is any direct evidence in favor of that hypothesis.

Elsie Moore (1986) [17] studied a pool of 46 adoptees, all of them black. Half were raised by white parents of high SES, half were raised by black parents who were equated with the whites for SES. The blacks reared by the whites had an advantage of 13.5 IQ points by age 8.5 . She invited the mothers in and observed them interacting with their child during problem-solving tasks. The white mothers were positive, smiling, and encouraging ("that's a good idea-why don't we try this"); the black mothers were negative, frowning, and discouraging ("you know better than that").

In sum, black subculture simply did not exist in Germany for half-black children raised by German mothers. It was not there to dictate a worse cognitive environment. They were simply dark skinned Germans. This may have carried its own penalty, but whatever that was it did not cripple them as they ascended the ladder of cognitive complexity. Political correctness prevents the study from being replicated today.

Flynn (2008) [18] provides an analysis of black American subculture that suggests that each succeeding black environment offers less cognitive stimulation than each successive white environment. Blacks lose ground on whites with age: with whites set at 100, black IQ values are 99.0 at 9 months (these tests are crude- using or not using a rod to pull toys toward you); 95.4 at 4 years; 92.4 at 9 years; 89.4 at 14 years; 86.4 at 19 years; 83.4 at 24 years [19].

Moore takes us to almost age 9 . To this, we must add that over $70 \%$ of black children are being raised in solo-parent (often poverty) homes. They are mainly exposed to child-to-child speech rather than hearing adult-to-adult speech. Some of these black mothers ration their own verbal interaction; why talk to him if he can't talk back. Many blacks then go into mainly black schools where initial skills, standards, and expectations are lower. Even before they are teens they encounter black teenage subculture, which tends to be a shopping mall subculture with an emphasis on dressing sharp and sexual prowess rather than academic achievement. Between 18 and 24, a majority of black women start the cycle of isolated solo-parent all over again and about one third of black men spend time in jail.

Where an overseas black culture dominates (different from that usual in America), the results are sometimes surprising. In 2010, there were 260,000 Nigerians in the US, which was $0.75 \%$ of the black population. Yet in 2013, 20-25\% of the 120 black students at Harvard Business School were Nigerians. Nearly $25 \%$ of Nigerian households have incomes of more than $\$ 100,000$ US-see Sowell, 2015 [20]. These immigrants are of course from an elite group within Nigeria. However, note how much better they fare compared to blacks who are the most elite of those produced by the black American subculture (those of high SES). These data are not decisive: Nigerian Americans may be fixated on Harvard Business School while black Americans in general aspire to a wider range of professions and universities. 


\section{Regression to the Mean}

Jensen and Rushton (2005) [12] rely on a pattern of regression as an argument for a genetic gap between black and white people. By age 21, children of high IQ white parents (average 115) tend to regress to a mean of 107.5, which is half way toward their population mean of 100 at that age. The children of high IQ black parents (average 115) tend to regress to a mean of 100, which is half way toward their population mean of 85 . The implication drawn is that these means are fixed by genetic differences.

The implication is false. If the IQ means of black and white were fixed by regression in 1972, the IQ gap could not have declined by five IQ points by $2002[19,21]$. In addition, the logic is flawed. Regression is a within-population phenomenon based on imperfect correlations. Since the correlation between a parent's IQ and child's IQ is about 0.50 for both races, this dictates a half way regression toward the population mean for both races.

The correlation between a parent's height and child's height is also 0.50 . Thus, if we picked an elite sample of parents using height, the child's height would regress-and it would regress to "whatever the population mean happened to be". Take a population whose mean is 6 feet and whose SD is 6 inches or half a foot. If we picked an elite group of parents using height as a criterion that averaged 7 feet tall (two SDs above the mean), their children would regress to one SD above that mean or 6.5 feet. Take another population whose mean is 5.5 feet and whose SD is also 6 inches. If we picked an elite group of parents using height as a criterion that averaged 6.5 feet tall (also two SDs above the mean), their children would regress to one SD above that mean or 6 feet.

What is an elite group supposed to regress toward, if not their own population's mean? To ask an elite sample of one population to regress to some other population's mean is no more sensible than asking an elite sample of cats to regress to the mean of a population of dogs. Regression to the mean tells us nothing about the differences between populations. This applies to information about what causes the means of two populations to be different. One population may be Americans from the 1900s, and the average height gain between the 1900s and Americans today may have been 6 inches, in which case environmental factors were mainly at work (better nutrition and so forth). Or the two populations may be contemporary Watusi and Pygmies, and the difference between their height means is mainly due to genetic differences.

If the argument about regression carries weight, it can only be because of a hidden assumption. The sample of high IQ black parents would tend to be black professionals. Rather than viewing them as part of the black population, should they not be viewed as part of the white population? Certainly this black elite must create an environment for their children akin to privileged whites, rather than an environment merely above that of average blacks. And if their environment puts them within the white population, the only handicap they can have is their inferior genes, which pull their children below white children from homes of the same status.

This reveals that the argument from regression is superfluous. If we can validly equate blacks with elite SES with whites with the same SES, the ball game is already over. Equating for SES leaves most of the IQ gap between black and white intact. If these two groups are environmentally equivalent, the very existence of an IQ gap settles the question of whether blacks have inferior genes-and no appeals to regression are needed. As we have seen, Elsie More calls this into question. Even when equated for high SES, blacks offer their children less cognitive stimulation, and less incentive to confront problems of cognitive complexity than white parents. To say nothing of the fact that black children are likely to be drawn into the ambit of black teenage subculture and so forth.

A number of analyses attempt to show that the environmental factors that differentiate blacks from whites are identical to those that differentiate whites from one another (show that blacks and whites can be treated as members of the same population). These open up a debate about whether what are apparently the same factors should be treated differently between groups and within groups, a debate that sidelines regression to the mean [22]. 
My explanation of the racial IQ gap by referring to subculture enrages orthodox American social scientists: they call it blaming the victim. It is respectable to say that blacks have lower SES (are poorer than whites) because that is not their fault. But since using SES cannot explain the racial IQ gap, these scholars can offer no real explanation at all. They merely talk in a general way about the legacy of slavery, and so forth. As if persistent effects from slavery, that still affect blacks today, would not be facets of contemporary cultural differences beyond SES. But again, blacks are "exonerated" because slavery was not their fault. While less effective child rearing and the intellectual poverty of back teenage culture seem like an indictment.

The penalty of not discovering the real factors that handicap blacks is, of course, that neither we nor they can isolate them and consciously improve their lot.

\section{The Ice Ages Hypothesis}

Lynn (1987) [23] and Rushton (1995) [24] posit that extreme cold creates a more challenging environment, one that maximizes selection for intelligence-related genes. During the Ice Ages, ancestors of East Asians are supposed to have been North of the Himalayas where the cold was most intense, the ancestors of whites North of the Alps where the cold was next worst, and the ancestors of blacks still in Africa where it was relatively warm. This hypothesis is advanced to explain a racial hierarchy of better genes for intelligence running from East Asians to whites to blacks.

In fact, the Chinese are really two distinct groups, one of which originally settled north of the Yangzi River and the other south of the Yangzi. The two have intermixed but genetic markers show whose genes are most prominent: southern genes are relatively absent in the north and become dominant as you go toward the south, particularly to southeast provinces like Guangdong [25]. While northern Chinese may have been north of the Himalayas during the last Ice Age, the southern Chinese took a coastal route from Africa to China. They went along the Southern coast of the Middle East, India, and Southeast Asia before they arrived at the Yangzi. They never were subject to extreme cold.

The Ice Ages hypothesis offers a prediction: the mean IQ of Chinese should drop as we go from north to south. The island republic of Singapore is a city-state. Virtually all of its people are from Guangdong, the most southeast of China's provinces. According to Lynn, it has a mean IQ of 108; if you isolate its Chinese population, they have a mean IQ of 114. Mainland China has 105. In addition, we now have a proper IQ map of China, which shows no tendency for mean IQ to fall as we go from north to south. Flynn (2013) [26] gives a full account.

This falsifies one evolutionary scenario but others may be forthcoming. I will only say that I am suspicious of these because none of us can go back and really evaluate environment and mating patterns. Given free rein, I can supply an evolutionary scenario for almost any pattern of current IQ scores. If blacks had a mean IQ above other races, I could posit something like this: they benefited from exposure to the most rigorous environmental conditions possible, namely, competition from other people. Thanks to greater population pressures on resources, blacks would have benefited more from this than any of those who left at least for a long time. Those who left eventually became Europeans and East Asians. Let anthropologists rather than psychologists come forward with something that can really be evidenced.

\section{Short-Cuts}

In conclusion, contrary to Rushton: the method of correlated vectors, whether the results are positive, neutral or negative, tells us nothing about whether a performance difference between two groups is genetic or environmental; regression to the mean tells us nothing (new) about whether the different means of two groups are created by genes or environment; there is at present no validated evolutionary scenario that shows how different IQ-related genes were dictated by more or less rigorous environments. The race and IQ debate is so challenging that it is only human to want a shortcut, but no shortcut works.

Acknowledgments: We gratefully acknowledge the support from Cambridge University Press. And the Journal of Biological Science permits us to use Table 1. 


\section{References}

1. Louie, S. Asian gambling addiction: More than just chance. Psychol. Today, 10 July 2014.

2. Chan, J.W.; Eysenck, H.J.; Lynn, R. Reaction times and intelligence among Hong Kong children. Percept. Mot. Skills 1991, 72, 427-433. [CrossRef]

3. Flynn, J.R. Reaction times show that both Chinese and British children are more intelligent than one another. Percept. Mot. Skills 1991, 72, 544-546. [CrossRef]

4. Jensen, A.R. Bias in Mental Testing; Methuen: London, UK, 1980.

5. Jensen, A.R. Clocking the Mind: Mental Chronometry and Individual Differences; Elsevier Science: Amsterdam, The Netherlands, 2006.

6. Te Nijenhuis, J.; Choi, Y.Y.; van den Hoek, M.; Valueva, E.; Lee, K.H. Spearman's hypothesis tested comparing Korean young adults with various other groups of young adults on the items of the Advanced Progressive Matrices. J. Biosoc. Sci. in press.

7. Te Nijenhuis, J.; van Vianen, A.; van der Flier, H. Score gains on g-loaded tests: No g. Intelligence 2007, 35, 283-300. [CrossRef]

8. Te Nijenhuis, J.; Voskuijl, O.F.; Schijve, N.B. Practice and coaching on IQ tests: Quite a lot of g. Int. J. Sel. Assess. 2001, 9, 302-308. [CrossRef]

9. Flynn, J.R. What is Intelligence? Beyond the Flynn Effect; (Expanded paperback edition); Cambridge University Press: Cambridge, UK, 2009.

10. Flynn, J.R. Are We Getting Smarter: Rising IQ in the Twenty-First Century; Cambridge University Press: Cambridge, UK, 2012.

11. Flynn, J.R. Does Your Family Make You Smarter? Nature, Nurture, and Human Autonomy; Cambridge University Press: Cambridge, UK, 2016.

12. Rushton, J.P.; Jensen, A.R. Thirty years of reserach on race differences in cogntive ability. Psychol. Public Policy Law 2005, 11, 235-294. [CrossRef]

13. Nyborg, H.; Jensen, A.R. Black-white differences on various psychometric tests: Spearman's hypothesis tested on American armed service veterans. Personal. Individ. Differ. 2000, 28, 593-599. [CrossRef]

14. Naglieri, J.A.; Jensen, A.R. Comparison of Black-White differences on the WISC-R and the K-ABC: Spearman's hypothesis. Intelligence 1987, 11, 21-43. [CrossRef]

15. Brody, N. Intelligence; Academic Press: Cambridge, MA, USA, 1992.

16. Flynn, J.R. Race, IQ, and Jensen; Routledge: London, UK, 1980.

17. Moore, E.G. Family socialization and the IQ test performance of traditionally and transracially adopted Black children. Dev. Psychol. 1986, 22, 317-326. [CrossRef]

18. Flynn, J.R. Where Have all the Liberals Gone? Race, Class, and Ideals in America; Cambridge University Press: Cambridge, UK, 2008.

19. Dickens, W.T.; Flynn, J.R. Black Americans reduce the racial IQ gap: Evidence from standardization samples. Psychol. Sci. 2006, 17, 913-920.

20. Sowell, T. Wealth, Poverty and Politics: An International Perspective; Basic Books: New York, NY, USA, 2015.

21. Flynn, J.R. The "Flynn effect" and the Flynn paradox. Intelligence 2013, 41, 851-857. [CrossRef]

22. Flynn, J.R. Reflections about intelligence over 40 years. Intelligence 2018, 70, 73-83. [CrossRef]

23. Lynn, R. The intelligence of the Mongoloids: A psychometric, evolutionary and neurological theory. Personal. Individ. Differ. 1987, 8, 813-844. [CrossRef]

24. Rushton, J.P. Race, Evolution, and Behavior: A Life History Perspective; Transaction Publishers: New Brunswick, NJ, USA, 1995.

25. Chen, J.; Zheng, H.; Bei, J.X.; Sun, L.; Jia, W.H.; Li, T.; Zhang, F.; Seielstad, M.; Zeng, Y.X.; Liu, J.; et al. Genetic structure of the Han Chinese population revealed by genome-wide SNP variation. Am. J. Hum. Genet. 2009, 85, 775-785. [CrossRef] [PubMed]

26. Flynn, J.R. Intelligence and Human Progress: The Story of What Was Hidden in Our Genes; Elsevier: London, UK, 2013.

(C) 2019 by the author. Licensee MDPI, Basel, Switzerland. This article is an open access article distributed under the terms and conditions of the Creative Commons Attribution (CC BY) license (http:/ / creativecommons.org/licenses/by/4.0/). 